\title{
AN INVESTIGATION ON THE BIOCONVERSION OF REFUSED RICE GRAINS TO ETHANOL
}

\author{
M. M. Naim* and M.E. Yehia**
}

\section{ABSTRACT}

Technology for production of bio-ethanol has been developed during the last two decades to the point at which large-scale production will be a reality in the next few years. This is to produce source of energy from some agricultural waste origin. The various raw materials used in the manufacture of ethanol via fermentation are conveniently classified into three main types of raw materials: sugars, starches and cellulosic materials. The objective of the present research is aimed at producing bio-ethanol by hydrolysis of refuse broken rice grains. Four procedures were attempted, of which the last one was the best and the maximum concentration reached of ethanol was $58.5 \%$. The broken rice grains were washed, dried and milled to a very fine product, followed by adjustment of $\mathrm{pH}$ with dilute acid, then cooked in a batch pressure cooker in slurry form. The slurry is then treated with several fungi to hydrolyze starch to dextrins, after which the mash is treated with a second fungus to reduce the dextrins to monosaccharides. The product was then fermented by baker's yeast saccharomyces cerevisiae (SC) into alcohol, the concentration of which was estimated by density determination of the clear filtrate at different time intervals. In order to separate the alcohol fraction, the liquid product can be either distilled or preferably subjected to separation by pervaporation (Pn) using different membranes of our choice which are fabricated in our lab. Dehydration or separation is accomplished by the use of the most suitable membrane with which the desired separation takes place. Furthermore, the byproduct left over can be further processed to reduce its water content then sold as animal food.

Key words: rice - saccharification - monosaccharides - fermentation - bioethanol-bioconversion - fungi-yeast.

*Prof., Chem. Eng. Dept., Faculty of Engineering. Alexandria University, Alexandria, Egypt

**Res, Rice Technology Training Center, Field Crops Research Institute, A.R.C., Alexandria, Egypt 


\section{INTRODUCTION}

$\mathrm{W}$ ith the inevitable depletion of the world's energy supply, there has been an increasing world-wide interest in alternative sources of energy. Therefore, growing attention has been devoted to the conversion of biomass into fuel ethanol, considered the cleanest liquid fuel alternative to fossil fuels. Significant advances have been made towards the technology of production of bioethanol through saccharification of biomass by different enzymes to monosaccharides followed by fermentation of the latter to ethanol. Simultaneous saccharification and fermentation (SSF) has also been investigated for the preparation of bio-ethanol.

According to Akoh et al (2008) starch can be converted to useful functional ingredients such as high-fructose and maltose syrups, wine, glucose, and trihalose. They studied the conversion process which involves fermentation by microorganisms and use of biocatalysts such as hydrolases of the amylase superfamily. Amylases catalyze the process of liquefaction and saccharification of starch. Continuous bioconversion of starch to ethanol by immobilized enzymes and yeasts was studied by

McGHEE et al (1984). Commercial corn starch (10\% b.w.) was first batch liquefied with bacterial $\alpha$-amylase. The liquefied starch was then converted to glucose with calcium-alginate-entrapped fungal glucoamylase, and the resulting glucose was fermented to ethanol by calcium-alginate-entrapped Fleischmann's active dry yeast. Hydrolysis of starch was also carried out by Roy and Gupta (2003) by a blend of individually entrapped glucoamylase and pullulanase (in calciumalginate beads) in the ratio of 3:2 (activity-wise).

To attain both high productivity and efficient recovery of ethanol from broth, a membrane bioreactor consisting of a jar fermentor and a Pn system was applied by Mori and Inaba (2005) in the direct production of ethanol from uncooked starch with a thermophilic anaerobic bacterium: Clostridium thermo-hydrosulfuricum. Giordano et al (2008) investigated the production of ethanol from starch using glucoamylase and SC coimmobilized in pectin gel by a continuous SSF process.

In a review by Lin and Tanaka (2006) a broad overview of the current status of ethanol fermentation including biomass resources, 
microorganisms, and technology was presented. Also, the promising prospects of ethanol fermentation were especially introduced. The prospects included fermentation technology converting xylose to ethanol, cellulase enzyme utilized in the hydrolysis of lignocellulosic materials, immobilization of the microorganism in large systems, SSF and sugar conversion into ethanol. Azmi et al (2009) conducted a preliminary experiment to test the effect of coculturing commercialized ragi tapai with SC in improving the ethanol production by reducing the accumulation of inhibitory concentration of reducing sugars which would enhance the amylolytic activity.

Chen et al (2008) showed that SC codisplaying Rhizopus Oryzae (RO) glucoamylase and Streptococcus Bovis (SB) $\alpha$ - amylase on the cell surface can be used for direct production of ethanol from uncooked raw starch. Lee et al (1991) developed a mathematical model that described the SSF of sago starch using amyloglucosidase and Zymomonas Mobilis (ZM) to ethanol. The optimal conditions of the fermentation process of brown rice, naked barley and cassava by ZM (CHZ2501) were investigated by Choi et al (2008). Suresh et al (1999) used SSF to produce ethanol from raw starch of damaged quality wheat and sorghum grains by utilising crude amylase preparation from B. subtilis (VB2) and amylolytic yeast strain SC (VSJ4). Various concentrations of damaged wheat and sorghum starch from 10 to $30 \% \mathrm{w} / \mathrm{v}$ were used and $25 \%$ was found to be optimum for damaged wheat and sorghum starch yielding 4.40 and $3.50 \% \mathrm{v} / \mathrm{v}$ ethanol respectively, whereas $25 \%$ raw starch of fine quality wheat and sorghum grains gave a yield of 5.60 and $5.00 \% \mathrm{v} / \mathrm{v}$ respectively. The process was carried out at $35^{\circ} \mathrm{C}, 5.8 \mathrm{pH}$ and $200 \mathrm{rpm}$ for 4 days.

The study on the presently disclosed subject matter provides improved processes for processing starch from plant sources, including processes for starch liquefaction, and for simultaneous liquefaction and saccharification. For the preparation of ethanol conducted by Bati et al (2009) these processes were performed without a $\mathrm{pH}$ adjustment and at relatively low temperatures. The process can involve the use of starchcontaining plant material derived from plants that express starchdigesting enzymes. The subject further relates to improved processes for 
the preparation of other starch - derived products including dried distiller grain and solubles and to the starch-derived products themselves.

Enzymatic hydrolysis of starch in corn is an important step that determines fermentation efficiency. Corn genetics, post-harvest handling and process conditions are factors that affect starch hydrolysis. A study on the possibilities of improving ethanol fermentation of nzymatically obtained corn semolina hydrolyzates with alginate- immobilized yeast SC var. ellipsoideus by medium supplementation with mineral salts as sources of magnesium, zinc, calcium and copper ions, and vitamins (pantothenate, thiamine, pyridoxine, biotin and inositol) separated or as combined mixtures, have been investigated by Nikoli et al (2009).

Ochoa et al (2008) proposed an unstructured and a cybernetic model that is a novel model, which especially considers i) the starch degradation into both glucose and dextrins, and ii) the dynamic behavior of the concentration of the main enzymes involved in the intracellular processes, giving a more detailed description of the process, and compared to SSF process from starch to ethanol (SSFSE), in order to have good, reliable, and highly predictive models, which can be used in optimization and process control applications. The economic competitiveness of ethanol as a liquid fuel strongly depends on the amount of energy used during the production. To a sustainable production of fuel ethanol contributes also the use of energy from renewable sources. A study on process simulation used to integrate a bioethanol plant in a network of facilities for heat and power production from residues of ethanol and feedstock production was carried out by Wukovits et al (2008). Results show that depending on plant capacity and form of biogas utilization it is possible to cover heat demand using biogas produced from stillage of bioethanol fermentation. Du Preez (2007) critically reviewed some ethanol fermentation technologies from sugar and starch feedstocks, particularly those key aspects that have been neglected or misunderstood. Compared with SC, the ethanol yield and productivity of $\mathrm{ZM}$ are higher, because less biomass is produced and a higher metabolic rate of glucose is maintained through its special EntnerDoudoroff pathway. However, due to its specific substrate spectrum as well as the undesirability of its biomass to be used as animal feed, this 
species cannot readily replace SC in ethanol production. Roychoudhury et al (1992) have developed a notable way of eliminating the negative effects which excessive concentrations of ethanol have on yeast activity and cellulose within the SSF system. They used a vacuum cycling reactor where the concentration of ethanol was kept at a relatively low level by its removal from the flash chamber. However, more efforts have to be made in the development of microorganisms for industrial ethanol production. In addition, it is important to keep the rate-limiting step in mind. In SSF, the ethanol production rate is controlled by the cellulose hydrolysis rate and not the glucose fermentation, and hence, steps to increase the rate of hydrolysis will lower the cost of ethanol production via SSF.

The aim of the present work is to prepare bio-ethanol from refused broken rice grains instead of being dumped or used as animal food.

\section{MATERIALS AND METHODS}

The present study was carried out during the 2008 rice growing season. A sample of the rice common short grains variety grown under the normal conditions at the farm of Rice Research \& Training Center, Sakha, Kafr El-Sheikh, was utilized in the production of bio-ethanol by hydrolysis of refuse broken rice grains at a laboratory in the chemical engineering department, faculty of engineering, Alexandria University and at the Rice Technology Training Center, Alexandria, Egypt.

\section{Materials}

Refused broken rice grains were used as the raw material. Barley was used to prepare diastase (mostly $\alpha$ - amylase enzyme plus little glucoamylase). Aspergillus niger was prepared in the lab in order to be a source of glucoamylase enzyme. Yeast (SC) was purchased from the market in packets and $\alpha$-amylase from Sigma (USA).

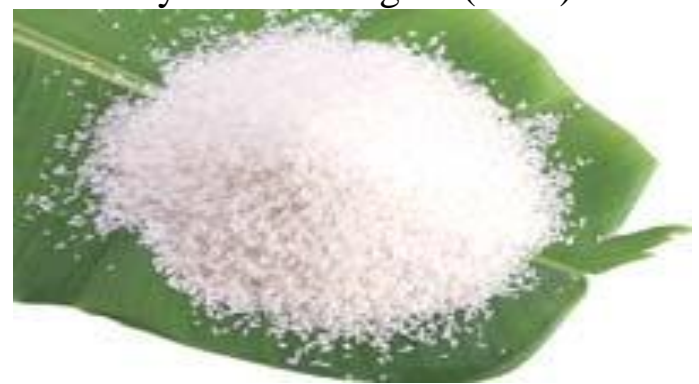

Figure (1) Milled refused broken rice 


\section{Apparatus}

A pressure cooker (Express 0.5- 1 bar pressure work, made in Morocco $8 \mathrm{~L}$ capacity) was used for steaming the finely milled rice. A simple shredder (Nelco Ltd, Shalford Surrey, rpm from 4000 to 14000, 110 volt) was used to shred the mixture of milled rice, distilled water and diastase.

\section{Methods}

Four different procedures were used in order to test the effect of the variables on the quantity of ethanol produced.

Method 1: A certain amount of cleanly washed milled rice was mixed with a suitable amount of distilled water in a beaker such that the water covered the rice. The mixture was heated to $35^{\circ} \mathrm{C}$. The yeast was added to the mixture and stirred at constant temperature in a water bath at $35^{\circ} \mathrm{C}$ for one hour. The mixture was filtered on a filter paper and the clear filtrate was ready for analysis. After 13 days at almost $35^{\circ} \mathrm{C}$ another sample was taken from the mixture, filtered in the same manner, and the filtrate was ready for analysis of ethanol present. After another 30 days from the last step the same operation was conducted and the filtrate was ready for analysis.

Method 2: The washed milled rice grains were steamed in the pressure cooker for a total time of $5.25 \mathrm{~h}$, after which the steamed rice was mixed with diastase enzyme and the whole mixture was put on an electric hot plate for $0.5 \mathrm{~h}$ while stirring at exactly $57^{\circ} \mathrm{C}$. Later the hot plate was adjusted to $35^{\circ} \mathrm{C}$ and a certain amount of yeast was added while keeping the temperature constant at $35^{\circ} \mathrm{C}$. Anaerobic experimental conditions were ensured by putting the mixture in a clean dry flask and covering it with cling wrap to ensure anaerobic conditions. Three samples were taken after five, seven and fourteen days consecutively while keeping the flask in a water bath at $30-35^{\circ} \mathrm{C}$ to keep the yeast activated. After 26 days a last sample was analyzed.

Method 3: 150 grams of the milled and washed rice grains plus $433 \mathrm{ml}$ distilled water were added to the flask followed by $300 \mathrm{ml}$ of enzyme diastase. The flask was placed into a $95^{\circ} \mathrm{C}$ water bath, and the contents were mechanically stirred with a 3 - bladed marine-type propeller. After 
the mixture was heated and stirred for 30 minutes at $95^{\circ} \mathrm{C}$, the temperature of the liquefied starch was raised to $100^{\circ} \mathrm{C}$ for 5 minutes to ensure sterilization. Later the mash was cooled to $35^{\circ} \mathrm{C}$, after which the $\mathrm{pH}$ of solution was adjusted to 4 using $\mathrm{pH}$ paper of a range 1:7 followed by confirmation of the $\mathrm{pH}$ by using another $\mathrm{pH}$ paper in the range 3.9:5.1 to make sure that the $\mathrm{pH}$ was exactly 4. The mixture was then transferred to a large beaker and diluted to $1800 \mathrm{ml}$, with distilled water (under sterilized conditions). The next step was to sterilize a knife over a bunsen flame followed by absolute alcohol in order to take a sample of suitable mass of the Aspergillus Niger and add it to the contents of the beaker then stirring by the shredder for 45 minutes at $40^{\circ} \mathrm{C}$. After agitation the large beaker was covered completely with transparent cling wrap and the whole left for exactly 2 days. After that a mixture of 11.211 grams of yeast in $280 \mathrm{ml}$ distilled water was added to the previous mixture and kept at $30^{\circ} \mathrm{C}$ while agitating for 30 minutes and the whole intimately mixed. The last step was to distribute this mixture in 9 bottles equipped with tightly fitting covers and each sealed with cling wrap to provide anaerobic conditions.

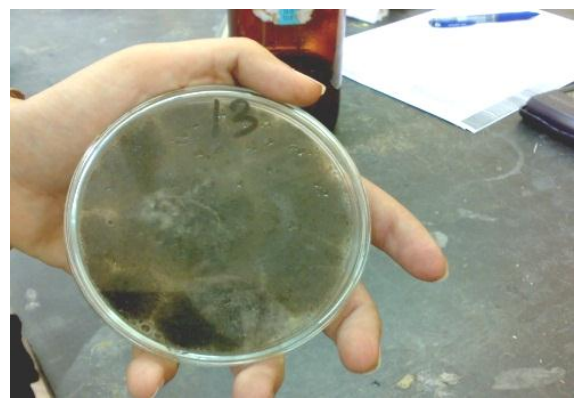

Figure (2) Fungi Aspergillus Niger

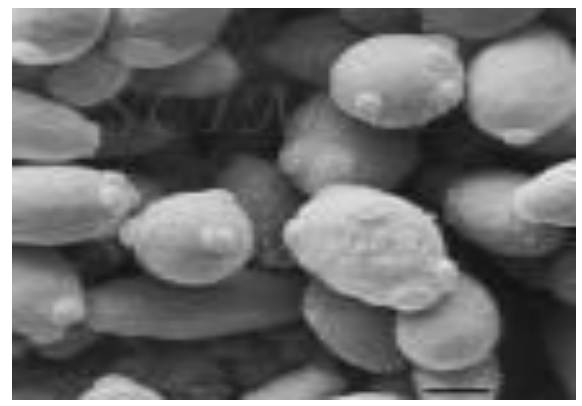

Figure (3) Magnified Saccharomyces Cerevisiae by SEM

Method 4: 150 grams of whole rice grains were washed, milled then mixed with $433 \mathrm{ml}$ of distilled water. One gram of $\alpha$ - amylase was then added to the mixture instead of diastase. The process was continued as in method 3 until dilution of the mash to $1800 \mathrm{ml}$ with distilled water (under sterilized conditions). The liquefied starch was then added to a large glass jar with an opening at its lower end. A Pyrex glass tube (height $=$ 
$35 \mathrm{~cm}$, diameter $=3.5 \mathrm{~cm}$ ) provided with a thin smaller tube at its bottom was packed with hydrophilic loofah Egyptiaca in a moderately compact manner. The liquid was drawn from the jar by a small centrifugal pump forcing it upwards through the stationery loofah packing, and then allowed to pass through polyethylene tubing to the top opening of the jar in a recycle mode. The temperature was kept at $35^{\circ} \mathrm{C}$, then the whole was mixed with 11.2 grams of baker's yeast $\mathrm{SC}$ with $280 \mathrm{ml}$ distilled water at $35^{\circ} \mathrm{C}$ and the whole agitated in the jar to form a uniform suspension, then recycling was continued such that anaerobic conditions were ensured. At different time intervals, a sample of the supernatant liquid was pipetted then filtered by a double Whatman filter paper fitted in a filter funnel in a clean dry test tube. A $2 \mathrm{ml}$ sample from the filtrate was pipetted by a clean dry $2 \mathrm{ml}$ pipette then added to a pre-weighed weighing bottle fitted with a sealed cover. The weight of the liquid was determined, then its density computed and the concentration of ethanol in the aqueous mixture determined from standard tables in Perry's handbook for chemical engineers (1979).

\section{Preparation of diastase (malt)}

Diastase was prepared by allowing barley to germinate at $14-17^{\circ} \mathrm{C}$ for about 7 days, after which it was heated with water at $57^{\circ} \mathrm{C}$ to stop germination, then the germinated barley was shredded using the shredder. The mixture was then filtered to obtain the diastase enzyme as filtrate.



Figure (4) Barley before and after germination

\section{Method of analysis}

The product bio-ethanol that has been filtered through a filter paper (version 102, made in China) to produce a clear filtrate was subjected to density determination according to the method by Naim and Yehia 
(2009) by rapidly pipetting a sample of the clear product into a plastic bottle fitted with a tight cover to avoid evaporation of the alcohol. The sample of known volume was weighed on an analytical electrical balance (DENVER instrument AA-160) to the $4^{\text {th }}$ digit. The density was computed, and then the concentration of ethanol as percent by weight determined from special tables found in Perry's handbook for chemical engineers (1979).

\section{RESULTS AND DISCUSSIONS}

Table (1) indicates the conditions of the experiments and sequences of the steps conducted for production of bio-ethanol by four different procedures.

Table (1): Conditions of all experiments and sequence of the steps conducted in each procedure for production of bioethanol

\begin{tabular}{|c|c|c|c|c|}
\hline \multirow{2}{*}{$\begin{array}{l}\text { Condition of } \\
\text { Experiment }\end{array}$} & \multicolumn{3}{|c|}{$\begin{array}{c}\text { Batch } \\
\text { Procedure }\end{array}$} & \multirow{2}{*}{\begin{tabular}{|l} 
Recycle \\
Procedure 4 \\
\end{tabular}} \\
\hline & 1 & 2 & 3 & \\
\hline Raw material & \multicolumn{3}{|c|}{ Broken refused rice } & \\
\hline Grinding then milling & - & $\sqrt{ }$ & $\sqrt{ }$ & $\sqrt{ }$ \\
\hline Steaming \& liquefaction & 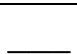 & $\sqrt{ }$ & $\sqrt{ }$ & $\sqrt{ }$ \\
\hline $\begin{array}{c}\text { Dextrinization } \\
\text { (addition of diastase) } \\
\text { (addition of } \alpha \text {-amylase) }\end{array}$ & - & $\sqrt{ }$ & $\sqrt{ }$ & $\sqrt{ }$ \\
\hline $\begin{array}{c}\text { Saccharification } \\
\text { (addition of Asperguillus Niger) }\end{array}$ & - & 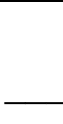 & $\sqrt{ }$ & - \\
\hline $\begin{array}{c}\text { Fermentation } \\
\text { (addition of yeast SC) }\end{array}$ & $\sqrt{ }$ & $\sqrt{ }$ & $\sqrt{ }$ & $\sqrt{ }$ \\
\hline
\end{tabular}


In the first method, it was found that no alcohol was formed, simply because there are, of course, many more considerations here than just the simple addition of yeast to a slurry of mashed refused rice. Fermentation to alcohol, like anaerobic digestion, is a biological process and requires special attention through a series of living reactions. For example pure yeast will not produce ethanol even from pure sugar, because a pure sugar solution does not contain the nutrients and other substances required to nourish the yeast. Actually, fermentation is a series of chemical steps, each one providing the basic materials for the others to follow in a succession of reactions. Accordingly, since the broken rice was not subjected to grinding then milling neither steaming to form a mash, in addition, $\alpha$-amylase was not added to the rice granules, and therefore dextrinisation did not take place. Similarly, gluco-amylase was not added to effect saccharification, thus on adding dissolved yeast, fermentation did not take place since no monosaccharides were formed to become fermented into ethanol. This result was expected but was proved experimentally to make sure that the results obtained later will be following the correct path.

In the second method, however, milling was followed by steaming to gelatinize the starch forming a mash, and then followed by the addition of diastase enzyme (prepared from the germinated barley) which converted the mash into a sugar solution. Diastase is found abundantly in all sprouted grains (malt), especially barley, thus grains are often sprouted before being used for fermentation. However, no glucoamylase was added to effect saccharification of the resulting dextrin, therefore after 7 days of fermentation, the quantity of bioethanol reached only $6.1 \%$ and after 20 days, the amount of ethanol just increased to 6.5 $\%$ ( see figure 5). This result proves that only partial saccharification took place along with a limited amount of dextrinization formed by the action of dextrose. To this end, fermentation by addition of SC yeast was limited due to the former saccharification step not providing sufficient monosaccharides to be fermented into bioethanol.

In the third method, the broken refused rice grains, were subjected to grinding then milling followed by steaming to form a mash then dexrinisation by the addition of diastase enzyme followed by 
saccharification by adding Aspergillus Niger then finally fermenting with SC yeast (i.e. all required steps were conducted) as explained in the experimental part in detail. The mixture was distributed in numerous bottles which were sealed well to provide anaerobic conditions. The samples were analyzed for bioethanol after 2, 4, 6, 8, 10, 12, 14, 15, and 16 days consecutively, i.e. each bottle was opened and analyzed at a different time interval.

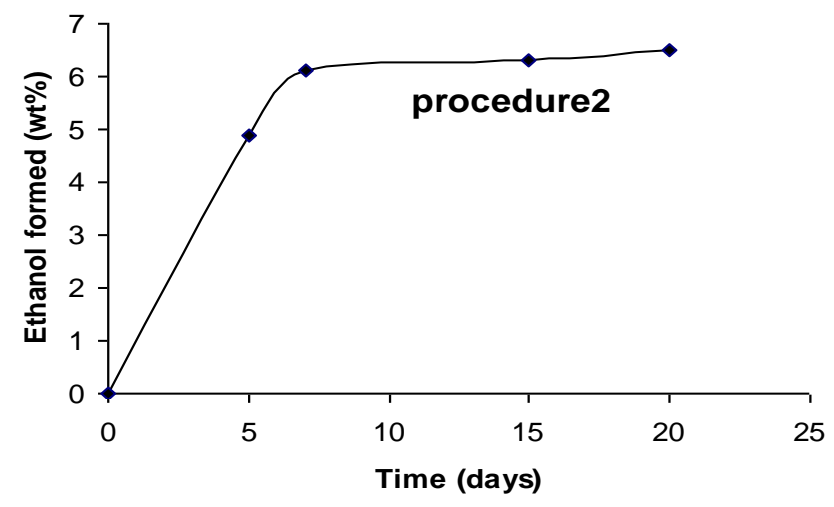

Figure (5). Effect of fermentation time on percentage bio-ethanol formed

In figure 5, which presents the effect of fermentation time on $\%$ bioethanol formed (by procedure 2) indicates that some fermentation took place in 20 days giving $6.5 \%$ bio-ethanol only. The aforementioned discussions apply also here. However, in figure (6) it is indicated that fermentation took place until a maximum of 8 days at which the bioethanol in the final liquor reached $13.57 \%$. It should be noted here that there are several consecutive rates of fermentation in which within 2 days the rate was moderate followed by a fast rate from 2-4 days, then the rate further decreased from 4-8 days at which the maximum \% alcohol was formed. From thereon till the day 14 the curve rapidly declined to about $8 \%$ alcohol, after which it suddenly declined steeply until on the $16^{\text {th }}$ day the alcohol had completely vanished. The reason for what took place is due to several facts:

Figure (6) shows the results expressed as \% alcohol formed (b.w.) versus time in days during the SSF operation conducted by procedure 3 . It is clear that during the first 2 days some glucose was formed which was 
converted to ethanol at a rather low rate, since it took time for starch to be transformed into dextrin plus some glucose. During the second stage (from day 2 to day 4) the rate of formation of alcohol was at its highest value as expected and shown by other workers. However, the third stage indicated that the rate of formation of ethyl alcohol declined until the day 8 at which the ethanol reached its maximum value (13.57\%). This was partly due to the retarding action of ethanol on the function of enzymes present and the SC yeast. From the day 8 to the day 14 the quantity of ethanol declined steadily due to the inhibitory effect of the present ethanol on both enzymes and yeast (breakdown). Accordingly, no more alcohol was formed; in fact it was consumed in breaking down the yeast and forming some lactic acid and acetic acid as well. From day 14 to day 16 a very rapid reduction in ethanol took place for the same aforementioned reasons until after the day 16 the alcohol vanished and we were left with water plus traces of lactic and acetic acids.

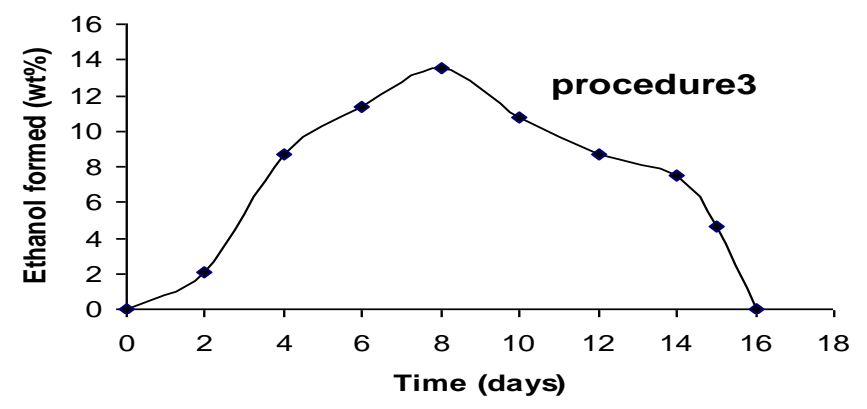

Figure (6).Effect of fermentation time on percentage bio-ethanol formed

Bacterial contamination of the fermentable sugar mixture (mash), either before or during fermentation, is considered one of the biggest problems encountered in alcohol yield, for which the chief protection against this is to monitor the $\mathrm{pH}$ or acidity control of the "mashing" and fermentation operations. However, even with perfect $\mathrm{pH}$ control bacterial infections can set in and typically happens during the cooling stage between mashing and fermentation. If bacterial contamination becomes a problem, a typical solution is to shorten the cooling time as much as possible, since the less time given at the temperatures conducive to bacterial growth, the better. A cooling coil in future could therefore help. 
It has been stated by Gulnur et al (1998) that glucose utilization, ethanol production, and growth pattern of yeast cells in a stirred batch system using four different initial substrate concentrations are inter-related. They studied the possibility of glucose or ethanol inhibition on both yeast cell growth and ethanol production by constructing eleven different mathematical models which took into account the aforementioned possibilities. A wide variety of models have been proposed by Mori et al (1970) and Namba et al (1984) for the kinetics of the process; these range from very simple models to more complex global models by Park et al (1990) and Park et al (1991), which take into account the activating and inhibiting effects of the substrate (glucose and oxygen) and the product Oh et al (2000). Moreover, structured models have been used to predict the influence of operating parameters on cell concentration, substrate utilization rate, and ethanol production rate. Although four factors (substrate limitation, substrate inhibition, product inhibition, and cell death) are known to affect ethanol fermentation, none of these models accounts for these kinetic factors simultaneously. The models of Hinshelwood (1946), Holzberg et al (1967), Egamberdiev and Jerusalimsky (1968), Nagatani et al (1968), and Hoppe and Hansfo rd (1982), account only for ethanol inhibition. The models of Aiba et al (1968), Aiba and Shoda (1969), and Luong (1985), include only substrate limitation and substrate inhibition terms. An appropriate ethanol fermentation model should therefore account for the four kinetic factors. It cannot be expected that any kinetic model will be directly applicable to a real process situation. Therefore, mathematical modeling should start with the simplest type, but it must be reiterated, modified, and extended until it eventually leads to an adequate process kinetic model.

Cellulose-to-ethanol biotransformation can be conducted by various anaerobic thermophilic bacteria as Ingram et al (1987) reported, as well as by some filamentous fungi, which were studied by Saddler and Chan (1982), Gong et al (1981), Pastore et al (1994), Sugawara et al (1994), Ito et al (1990), and Gervais and Sarrette (1990). However, studies on the fermentation process utilizing these microorganisms have shown this process to be very slow (3-12 days) with a poor yield $(0.8-60 \mathrm{~g} / \mathrm{l}$ of ethanol), which most probably is due to the low resistance of 
microorganisms to higher concentrations of ethyl alcohol. Another disadvantage of this process (particularly in the case of bacterial fermentation) is the production of various by-products, primarily acetic and lactic acids as reported by Herrero and Gomez (1980), which was realized in our present work.

The curve in figure (6) indicates that in the present work fermentation should have been terminated after the elapse of 8 days only during which the concentration was $13.57 \%$ ethanol.

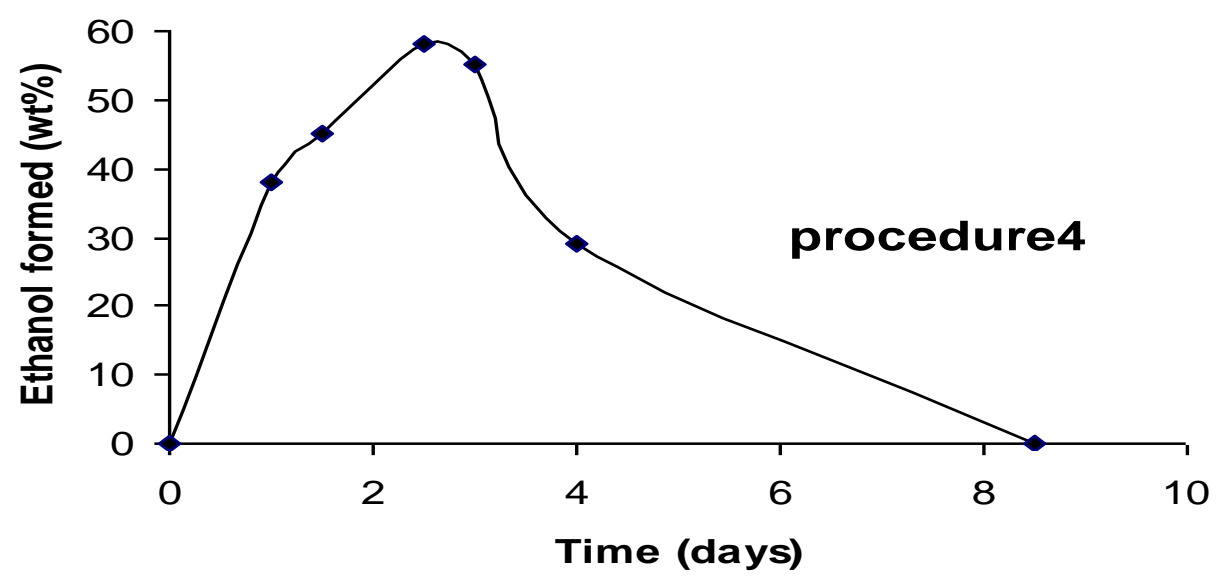

Figure (7) Relationship between \% bio-ethanol with time

Figure (7) shows that a much higher concentration of ethyl alcohol was obtained than the three previous methods, which was due to the good quality of $\alpha$ - amylase which is better than the enzymes which were prepared in our lab, in spite that only the amylase fraction of the starch was transformed into glucose and not the amylopectin, since glucoamylase was not used. Accordingly, the highest concentration of ethyl alcohol was achieved after almost 2 days. Half a day later the curve obtained was a very smooth one and beyond 2.5 days the percent concentration of bio-ethanol sharply decreased until it became zero after 8.5 days. The same aforementioned discussions of the previous figure pertaining to method 3 apply here as well. It is observed that the maximum concentration attained was 58.5 bio-ethanol (wt \%). 


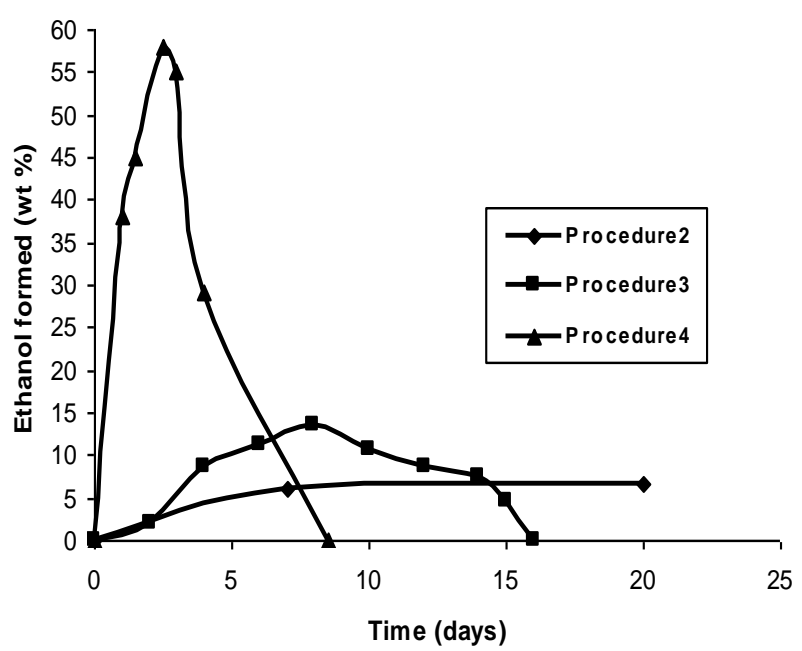

Figure (8) Comparison of the different procedures which shows relationship between $\%$ bio-ethanol with time

A comparison between the aforementioned procedures relating \% bioethanol formed versus time of operation in days is presented in figure 8 . In procedure 1 , no bioethanol was formed as mentioned before and which was expected and carried out on purpose for comparison. Procedure 2 is shown to produce only around $6.5 \mathrm{wt} \%$ bioethanol, the conditions clarified in table 1. Procedure 3 in which every step was accomplished except the addition of $\alpha$ - amylase, indicates that a maximum of $13.57 \mathrm{wt} \%$ bioethanol was produced in 8 days after which the curve declined to zero in 16 days. Lastly, procedure 4 produced the highest concentration which was $58.5 \mathrm{wt} \%$ bioethanol in a maximum of almost 2.5 days after which the bioethanol rapidly declined to stop producing bioethanol in almost 8.5 days. This result was achieved after grinding, milling steaming and dextrinization then saccharification of the straight chain $\alpha$ - amylose through the addition of $\alpha$ - amylase, and finally, fermenting the product under suitable conditions of $\mathrm{pH}$ and addition of yeast (SC).

Gilson and Thomas, (1995), developed a model for a fluidized-bed reactor with yeast cells immobilized on alginate beads. It was shown that the observed reduction in ethanol yield compared to free yeast cells was caused by substrate restrictions inside the beads and not by changes in the metabolic rate of the immobilized cells. Maia and 
Nelson,( 1993) presented a model of gravitational sedimentation intended to describe the recycling of cells to the bioreactor using a parallel plate sedimentary during continuous fermentation, which allowed the optimization of the operating conditions in order to efficiently recycle yeasts at high cell density similar to method 4 in which recycling through the loofah containing column was effected.

There exist different possibilities for reaction- reaction integration during production of ethanol from biomass especially from starch in particular when several operations can be carried out in a same single unit by which the possibilities for improving the performance of the global process are higher.

\section{CONCLUSIONS}

The present investigation demonstrated that bio-ethanol could be prepared by saccharification of either refused broken-or whole grain-rice followed by fermentation to different concentrations depending on the method followed. In method 1, it was clear that if saccharification is not effected at first, no matter how long a time is given for the yeast, for fermentation, no bio-ethanol is formed since no sugar existed to undergo fermentation to ethanol. This result was expected but was proven experimentally to make sure that the results obtained later will be following the correct path. In method 2, in which milling was followed by steaming and liquefaction of the starch forming a mash, and then followed by dextrinisation by the addition of diastase prepared from barley- however, no glucoamylase was added to effect saccharification of the resulting dextrin to glucose. Therefore, after 7 days of fermentation the quantity of ethanol reached $6.1 \%$ and reached $6.5 \%$ only after 20 days. This result proves that a little saccharification took place along with the dextrin formed by the action of diastase. However, in method 3 all the required sequential steps were carried out, accordingly, dextrinization by diastase plus a little sacharification to glucose and little xylose followed by further sacharification of the dextrin by Aspergillus niger and finally fermentation by SC resulted in a better yield $(13.57 \%$ bioethanol) due to the saccharification step. However, due to the diastase being prepared by us, it only produced a small fraction of monosaccharides. In addition, Aspergillus niger contains partly $\alpha-$ 
cellulase, therefore due to the glucose being formed only to a little extent, thus the alcohol formed was only 13.57 (wt \%) which was still to be improved. Nevertheless, it should be put in mind that the xylose formed due to saccharification of hemi-cellulose is not fermented by SC yeast, which contributes to decreasing the yield of the ethanol. Also the presence of ethanol inhibits the action of the yeast, therefore the production of glucose is reduced by time causing the yield of the ethanol to drop. It is worth mentioning here that besides bio-ethanol, lactic-and acetic-acids, furfural and di-methyl furfural are also produced in very small quantities and are considered as toxic inhibitors to the action of the (SC). Lastly, it should be mentioned that the best yield of ethanol in the case of procedure 4 was due to recycling the liquid under the proper conditions used, through the loofah packing which resulted in the reaction (fermentation) to take place at the surface of packing, which accelerated fermentation leading to a maximum of 58.5 (wt \%) bioethanol in 2.5 days. It is expected that further work using larger autoclaves and fermentors, together with the addition of some vitamins and inorganic salts during fermentation plus the use of immobilized yeast in columns would altogether enhance the productivity of the formed ethanol.

\section{REFERENCES}

Aiba S, Shoda M (1969) Reassessment of the product inhibition in alcohol fermentation. J. Ferment Technol. 47:790-803.

Aiba S, Shoda M, Nagatani M (1968) Kinetics of product inhibition in alcoholic fermentation. Biotechnology Bioengineering 11: 846864.

Akoh, C.C.; Chang, S-W.; Lee, G-C.; Shaw, J-F. (2008) Biocatalysis for the Production of Industrial Products and Functional Foods from Rice and Other Agricultural Produce, J. Agric. Food Chem., Vol. 56, 10445-10451.

Azmi, A.; Hasan, M.; Mel, M.; Ngoh, C. (2009) Single-step bioconversion of starch to bioethanol by the coculture of ragi tapai and Saccharomyces cerevisiae, Chemical Engineering Transaction Vol. 18, 557-562. 
Batie,C.J.; Crabb,G.; Aux,G.W.; Cates,E.S.; Dinwiddie,J.A; Silverstone,A.L.;_Quadt,R.; Miller,C.A." „Process for Starch Liquefaction and Fermentation", Syngenta Biotechnology, INC.;Patent Department, US 2009/0047382 A1 .

Chen, J-P.; Wu, K-W.; Fukuda, H. (2008) Bioethanol production from uncooked raw starch by immobilized surface-engineered yeast cells, Appl Biochem. Biotechnol, 145, 59-67.

Choi,G-W.; Kang,H-W.; Kim,Y-R.; Chung,B.W. (2008) Ethanol production by Zymomonas mobilis CHZ2501 from industrial starch feedstocks, Biotechnology and Bioprocess Engineering, vol.13, 765-771.

Egamberdiev NB, Jerusalimsky A (1968) Continuous cultivation of microorganisms. Czechoslovak Academy of Sciences, Prague.

Gervais P, Sarrette M (1990) Influence of age of mycelia and water activity on arpma production by Trichoderma viride. J Ferment Bioeng 69:46-50.

Gilson, C.D., Thomas, A., (1995) Ethanol production by alginate immobilized yeast in fluidized bed bioreactor. Journal of Chemical Technology and Biotechnology 62, 38-42.

Giordano, R.L.C.; Trovati,J.; Schmidell,W. (2008) Continuous Production of Ethanol from Starch Using Glucoamylase and Yeast Co-Immobilized in Pectin Gel, 147, 47-61.

Gong CS, Maun CM, Tsao GT (1981) Direct fermentation of cellulose to ethanol by a cellulolytic filamentous fungus Monilia ap. Biotechnol Lett 3:77-82.

Gulnur B, Pemra D, Betul K, Ilsen O, Kutlu U (1998) Mathematical description of ethanol fermentation by immobilized Saccharomyces Cererisiae. Process biochem 33(7):763-771.

Herrero AA, Gomez RF (1980) Development of ethanol tolerance in Clostridium thermocellum: effect of growth temperature. Appl Biochem Biotechnol 34/35:639-649.

Hinshelwood CN (1946) Kinetics of the bacterial cell. Oxford University Press. London, UK. 
Holzberg I, Finn RF, Steinkraus KH (1967) A hinetic study of the alcoholic fermentation of grape juice. Biotechnol Bioeng 9:413423.

Hoppe GK, Hansford GS (1982) ethanol inhibition of continuous anaerobic yeast growth. Biotechnol Lett 4: 39-44.

Ingram LO, Conway T, Clark DP, Sewell GW, Preston JF (1987) Genetic engineering of ethanol production in Escherichia coli. Appl Environ Microbiol 53:2420-2425.

Ito K, Yoshida K, Ishikawa T, Kobayaashi S (1990) Volatile compounds produced by fungus Aspergillus oryzae in rice koji and their changes during cultivation. J Ferment Bioeng 70:169-172.

J. C. du Preez, Fiona de Jong, P. J. Botes and P. M. Lategan (2007 ) Ethanol fermentation technologies from sugar and starch feed stocks , Elsevier Inc., vol.26, 89-105.

Lee, C.G.; Kim, C.H., Rhee, S.K. (1991) A kinetic model and simulation of starch saccharification and simultaneous ethanol fermentation by amyloglucosidase and Zymomonas mobilis, Bioprocess and biosystems engineering, vol.7, 335-341.

Lin, Y.; Tanaka, S. (2006) Ethanol fermentation from biomass resources: current state and prospects, Appl Microbiol Biotechnol, 627-642.

Luong JHT (1985) Kinetics of ethanol inhibition in alcohol fermentation. Biotechnol Bioeng 27:280-285.

Maia, A.B.R.A., Nelson, D.L., (1993) Application of gravitational sedimentation to efficient cellular recycling in continuous alcoholic fermentation. Biotechnology and Bioengineering 41, 361-369.

McGHEE, J. E.; CARR, M. E.; JULIAN, G. ST. (1984) Continuous Bioconversion of Starch to Ethanol by Calcium-Alginate Immobilized Enzymes and Yeasts, The American Association of Cereal Chemists. Inc. VOI.61, No.5, 446-449.

Mori A, Konno N, Terui G (1970) Kinetic studies on submerged acetic acid fermentation. I. Behaviors of Acetobacter rancens cells towards dissolved oxygen. J Ferment Technol 48:203-212. 
Mori, Y; Inaba, (2005) Ethanol production from starch in a pervaporation membrane bioreactor using Clostridium thermohydrosulfuricum, Wiley Periodicals, Inc., 36,_849 - 853.

Nagatani M, Shoda M, Aiba S (1968) Kinetics of product inhibition in alcoholic fermentation. J Ferment Technol 46:241-249.

Naim, M. M.; and Yehia, M. E.; (2009) A novel and simple technique for the determination of quantity of alcohol produced in wet paddy rice due to fermentation Misr Journal of Agricultural Engineering. Vol. 26 No. (4).

Namba A, Tamura A, Nagai S(1984) Synergistic effects of acetic acid and ethanol on the growth of Acetobacter sp. J Ferment Technol 62(6):501-505.

Nikoli, S.; Mojovi,L.; Pejin,D.; Rakin,M.; Vucurovic,v. (2009) Improvement of Ethanol Fermentation of Corn Semolina Hydrolyzates with Immobilized Yeast by Medium Supplementation , Food Technol. Biotechnol, vol. 47, 83-89.

Ochoa, S.; Yoo, A.; Repke, J-U.; Wozny, G.; Yang, D.R. (2008) Modeling and identification of the bio-ethanol production process from starch: Cybernetic vs. unstructured modeling, Elsevier B.V., vol. 25, 707-712.

Oh KK,Kim SW, Jeong YS, Hong SI (2000) Bioconversion of cellulose into ethanol by nonisothermal simultaneous saccharification and fermentation. Appl Biochem Biotechnol 89:15-30.

Park YS, Kiyoshi T, Fukaya M, Okumura H, Kawamura Y (1991) Production of a high concentration acetic acid by Acetobacter aceti using a repeated fed-batch culture with cell recycling. Appl Microbiol Biotechnol 35:149-153.

Park YS, Ohtake H, Toda K (1990) A kinetic study of acetic acid production by liquidsurface culture of Aceetobacter aceti. Appl Microbiol Biotechnol 33:259-263.

Pastore GM, Park YK, Min DB (1994) Production of a fruity aroma by Neurospora from beiju. Mycol Res 98: 25-35. 
Perry, R. H.," Perry's chemical engineer's handbook", McGraw hill, $7^{\mathrm{TH}}$ edition, 1979.

Roy, I; Gupta,M.N. (2003) Hydrolysis of starch by a mixture of glucoamylase and pullulanase entrapped individually in calcium alginate beads ,Elsevier Inc.,VOL.34, 26-32.

Roychoudhury PK, Ghose TK, Ghosh P (1992) Operational strategies in vacuum-coupled SSF for conversion of lignocellulose th ethanol. Enzyme Microb Technol 14:581-585.

Saddler JN, Chan MKH (1982) Optimization of Clostridium thermocellum growth on cellulose and pretreated wood substrates .Eur J Appl Microbiol Biotechnol 16:99-10-4.

Sugawara E, Hashimoto S, Sakurai Y, Kobayashi A(1994) Formation by yeast of the HEMF (4-hydrpxy-2 (or 5)-ethyl-5 (or 2)-methyl-3 (2H)-furanone) aroma components in Miso with aging. Biosci Biotechnol Biochem 58:1134-1135.

Suresh,K.; Kiransree,N.;Rao,L.V.(1999) Production of ethanol by raw starch hydrolysis and fermentation of damaged grains of wheat and sorghum, Bioprocess and Biosystems_Engineering, vol.21, 165168.

Wukovits,W.; Pfeffer,M.; Liebmann,B.; Friedl,A (2008) Integration of the bio-ethanol process in a network of facilities for heat and power production from renewable sources using process simulation, Elsevier B.V., vol. 24, 1295-1300.

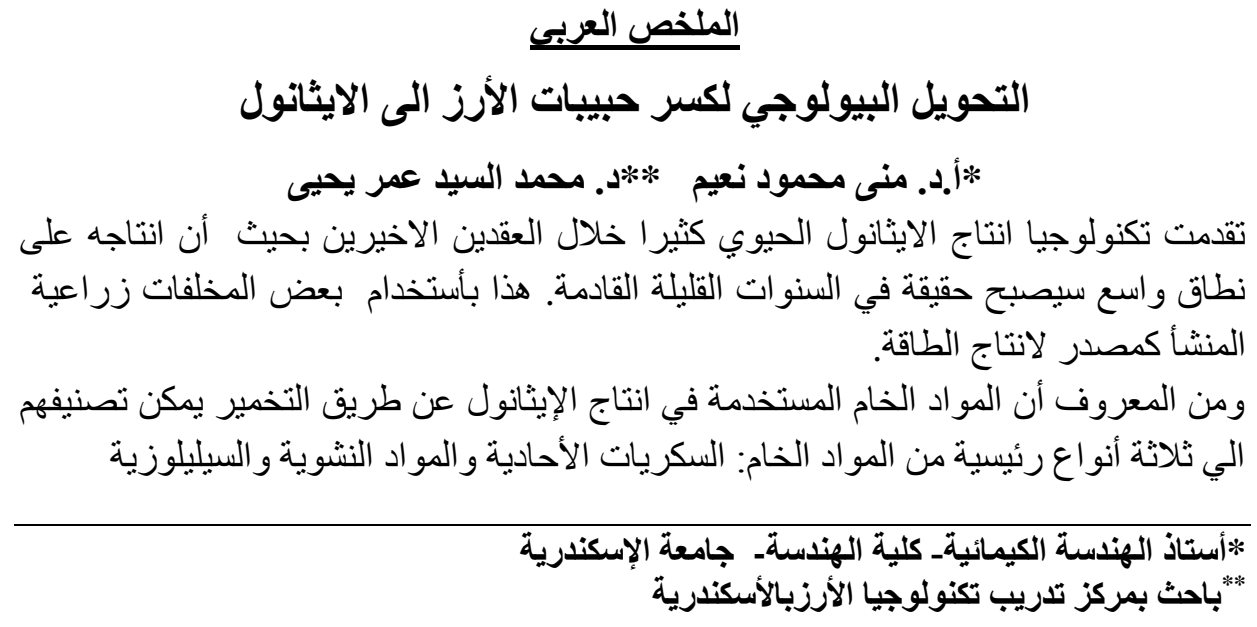


ويهدف البحث الحالي الى انتاج الإيثانول الحيوي من التحلل المائي لحبيبات الأرز المكسور

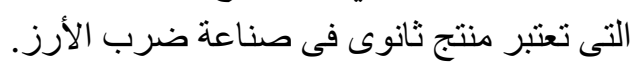

ولقد استخدمت اربعة إجر اءات مختلفة والتي وجد ان الأخيرة كانت الأفضل حيث وصل تركيز

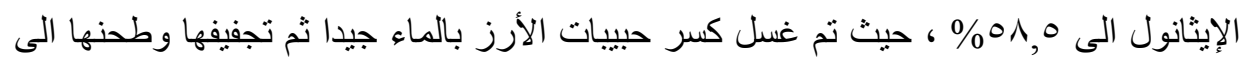

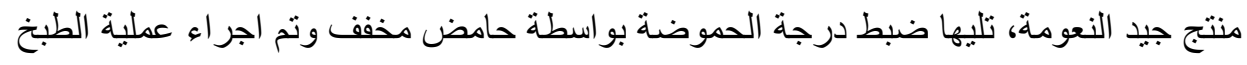

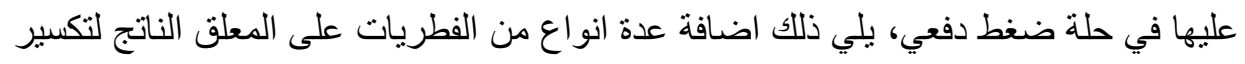

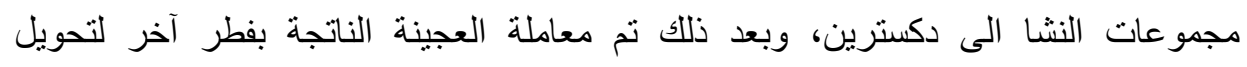

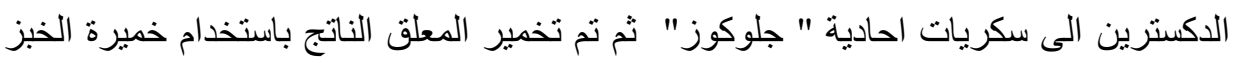
(saccharomyces cerevisiae)

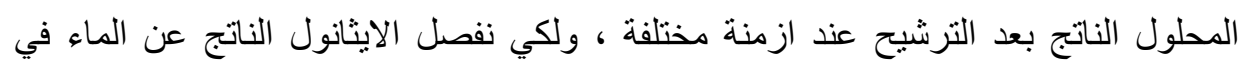

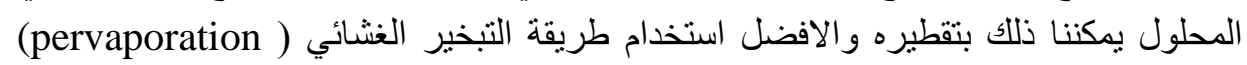

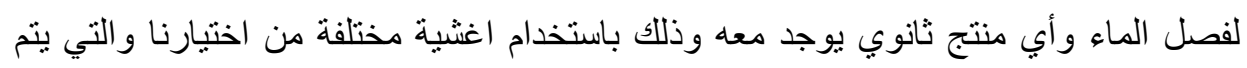

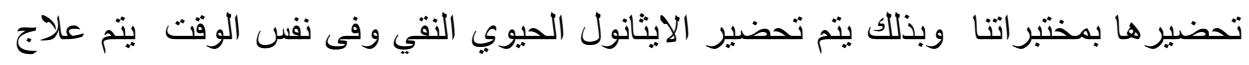

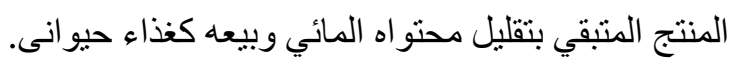

